\title{
Conflicto armado y terrorismo en Colombia. EI terrorismo de las Farc-EP de acuerdo con la Jurisprudencia de la Corte Constitucional colombiana
}

\author{
Armed conflict and terrorism in Colombia. The terrorism of \\ the FARC-EP according to the jurisprudence of the Colombian \\ Constitutional Court
}

\begin{abstract}
Henry Torres Vásquez
Abogado por la Universidad Nacional de Colombia: doctor en Sistema Penal por la Universidad Jaime I de Castellón. España; posdoctorado Universidad de Valencia, España. Docente investigador Facultad de Derecho Universidad La Gran Colombia, Bogotá (Col.); profesor posgrados en Derecho Penal, Universidad Nacional de Colombia, Santo Tomás, Libre, Militar, de Nariño, Gran Colombia y Universidad Pedagógica y Tecnológica UPTC - Tunja (Col.). Correo electrónico: henry.torres@ugc.edu.co
\end{abstract}

\begin{abstract}
Resumen
En Colombia se negó la existencia del conflicto armado interno y en otras oportunidades se reconoció que había disturbios o tensiones internas y que las Farc-EP no cumplían los requisitos establecidos en los Convenios de Ginebra y sus protocolos adicionales; en consecuencia, aspectos de enfrentamientos bélicos no eran en absoluto determinantes para señalar que había un conflicto armado interno, y en cambio, en muchas ocasiones en el siglo XX y lo que va de este, se dijo que existía una amenaza terrorista. Respecto al tema la Corte Constitucional ha venido planteando aspectos que tienen que ver con el conflicto armado interno en Colombia y junto a él se ha ocupado del terrorismo como uno de los problemas principales generadores de violencia. El tema del terrorismo efectuado por las Farc-EP ocupa específicamente la atención en cuanto este grupo es ahora (2015) considerado como una de las partes en el conflicto armado acaecido en Colombia durante cinco décadas. El presente artículo pretende analizar en clave de proyección, el terrorismo en un eventual posconflicto, determinando algunos aspectos de la jurisprudencia de la Corte Constitucional colombiana con relación al conflicto armado interno y la incidencia que estas decisiones han tenido respecto al terrorismo sucedido en este país.
\end{abstract}

Palabras clave: Conflicto armado, terrorismo, posconflicto, Corte Constitucional, Farc-EP.

\begin{abstract}
In Colombia he denied the existence of the internal armed conflict and on other occasions it was recognized that internal disturbances and tensions and the Farc-EP did not meet the requirements of the Geneva Conventions and its additional protocols; accordingly aspects of armed conflicts were not decisive to point out that all had an internal armed conflict and, instead, often in the twentieth century and so far this is said there was a terrorist threat. On the issue the Constitutional Court has been raising issues that have to do with the internal armed conflict in Colombia and with it has dealt with terrorism as one of the main problems generate violence. The issue of terrorism carried out by the Farc-EP specifically addresses the attention as this group is now (2015) considered as one of the parties to the armed conflict that occurred in Colombia for five decades. This article aims to analyze key projection terrorism in an eventual post-determining aspects of the jurisprudence of the Colombian Constitutional Court in relation to the internal armed conflict and the impact these decisions have on terrorism happened in this country.
\end{abstract}

Keywords: Armed conflict, terrorism, post-conflict, Constitutional Court, Farc-EP. 


\section{Résumé}

En Colombie, il a nié l'existence du conflit armé interne et à d'autres occasions, il a été reconnu que les troubles et tensions internes et que les FARC-EP ne répondait pas aux exigences des Conventions de Genève et ses protocoles additionnels; donc les aspects des conflits armés ne sont pas du tout important de noter qu'il y avait un conflit armé interne, et au lieu, à plusieurs reprises au cours du XXe siècle, et jusqu'à présent, cela est dit qu'il y avait une menace terroriste. Sur la question de la Cour constitutionnelle a soulevé des questions qui ont à voir avec le conflit armé interne en Colombie et avec lui a adressé le terrorisme comme l'un des principaux problèmes de génération de violence. La question du terrorisme menée par les offres des FARCEP spécifiquement l'attention que ce groupe est maintenant (2015) considéré comme l'une des parties au conflit armé qui a eu lieu en Colombie depuis cinq décennies. Cet article vise à analyser la projection centrale du terrorisme dans un post-conflit par la suite, la détermination de certains aspects de la jurisprudence de la Cour constitutionnelle colombienne en relation avec le conflit armé interne et l'impact que ces décisions ont eu sur le terrorisme qui est arrivé dans ce pays.

Mots-clés: les conflits armés, le terrorisme, post-conflit, la Cour constitutionnelle, les FA 


\section{Conflicto armado y terrorismo en Colombia. El terrorismo de las Farc-EP de acuerdo con la Jurisprudencia de la Corte Constitucional colombiana"}

Henry Torres Vásquez

\section{LA INVESTIGACIÓN}

En la historia de Colombia algunos gobiernos hablaron del terrorismo como una evidente amenaza; sin embargo, en el ámbito internacional a las Fuerzas Armadas Revolucionarias de Colombia (en adelante Farc-Ep) se les reconocía como organización guerrillera. Ya fuesen guerrilleros o terroristas los integrantes de este grupo ocasionan problemas de seguridad. Esta circunstancia en efecto produjo un sinnúmero de normas para solventar el problema de la inseguridad que la violencia producía en todo el país. En la década del ochenta y del noventa el terrorismo efectuado por carteles de la droga era de tal magnitud que no había una especial preocupación por el terrorismo de las Farc-EP, el cual sin embargo era perseguido. A partir del 2001 y posterior a los atentados terroristas en Estados Unidos, y debido a la confusión y al colapso surgido por el miedo generalizado que causó en todo el mundo el terrorismo, el concepto de acto terrorista se ha ido ampliando y abarcando todo el espectro legislativo mundial. Según Albrecht (2006, p. 1141) refiriéndose a la Resolución 1373 celebrada el 28 de septiembre de 2001 por el Consejo de Seguridad de las Naciones Unidas, esta decisión alentó la escalada de acciones represivas en todo el mundo, mediante un consentimiento forzado, lo cual no es de extrañar dentro de las políticas internacionales en torno al tema de la seguridad mundial. Aunque se condenó los ataques terroristas ocurridos en Nueva York, Washington, D.C., y Pennsylvania, dicha Resolución sentó una base política sólida para luchar y tratar de erradicar el terrorismo sin importar los medios o los métodos empleados. Es decir, todo lo que en contra del terrorismo se hiciera era patrocinado o avalado por el Consejo de Seguridad de la ONU. En ese contexto internacional y por la sensación de inseguridad del gobierno de Andrés Pastrana (1998-2002) surge como un "gran salvador" del terrorismo doméstico colombiano el señor Álvaro Uribe Vélez, quien en aquel momento era candidato presidencial, este recondujo la deteriorada apreciación del conflicto armado interno y

* Artículo que hace parte de la investigación terminada: Análisis del terrorismo en el marco de la justicia transicional en Colombia, financiado por la Facultad de Derecho de la Universidad La Gran Colombia, Bogotá, D. C. 
en cambio señaló que en Colombia no solamente no existía un conflicto armado interno, sino que existía una amenaza terrorista. Discurso que a través del "Plan Patriota" fue ejecutado en el gobierno de Uribe. Dicho plan fue financiado por Estados Unidos y ocasionó una ofensiva militar dirigida contra las Farc-EP (Faivre d'Arcier, 2006), lo que de algún modo agudizó el conflicto, con el argumento de ser un grupo terrorista. Esta instrumentalización del terrorismo finalmente lo llevó a la presidencia de este país del 2002 al 2006 y, posteriormente, le sirvió como bandera política para un segundo periodo 2006 al 2010. Por su parte las Farc-EP desde 1997 estaban incluidas en listas norteamericanas como organización terrorista, esa consideración igualmente la tuvo el gobierno de Pastrana (1998-2002) después de los hechos ya enunciados en Estados Unidos en el 2001. A partir de allí Colombia pidió incluso a la comunidad europea y por supuesto a los Estados Unidos ratificar la inclusión de aquel grupo en la lista de grupos terroristas, lo que ocurrió desde noviembre del 2002 en la presidencia de gobierno Uribe. Durante los dos gobiernos de Uribe las Farc-EP fueron perseguidas aunque no derrotadas, y sin embargo, este gobernante trató de concertar con ellos su práctica terrorista y una salida negociada al conflicto armado. Según publicó la Revista Semana, este presidente les ofreció a las guerrillas de las Farc-EP y al ELN "una zona de despeje, curules en el Congreso, eliminar la extradición, rebajas de penas, cese bilateral del fuego, reconocer el conflicto armado y hasta una Constituyente" (Revista Semana, 21/10/2014). Este aspecto es de mayor importancia si se tiene en cuenta que finalmente en el segundo gobierno de Santos (2014-2018) se sentaron a dialogar el gobierno y las Farc-EP; en otras palabras, el Gobierno y un grupo terrorista. Es claro que, tal como lo tienen previsto numerosos tratados y acuerdos internacionales suscritos y ratificados por Colombia, con terroristas no se negocia. Una actitud en contrario, implica que se desconozca la supremacía de las normas internacionales sobre las nacionales.

De ahí que se requiere analizar el dilema que yace del conflicto armado interno en Colombia y determinar si la solución al conflicto por la vía de acuerdos de paz en los que se llegue a una justicia de transición, y si de ese modo se termina con el rótulo de terroristas dado permanentemente a las Farc-EP por parte del Gobierno nacional e inclusive internacional. Dicho análisis es posible si se atiende a lo señalado por la Corte Constitucional a través de su jurisprudencia respecto a establecer si en Colombia hay o no conflicto armado interno, y consecuentemente cuáles son los argumentos que esta corporación tiene para calificar este grupo de terrorista o de guerrillero (Huertas, 2013). Se acude a esta Corte principalmente porque es la garante de la Constitución y la ley, y como es lógico pensar esta analiza los acuerdos y tratados internacionales suscritos y ratificados por Colombia, haciendo una evaluación de no ser atentatorios contra derechos fundamentales o derechos humanos.

En este orden de ideas, la Corte Constitucional mediante la Sentencia C-127 de 1993 determinó que el terrorismo es:

Un delito dinámico y se diferencia por tanto de los demás tipos. Como conducta responde a unas características diferentes de cualquier tipo penal, por lo siguiente: 
Primero, es pluriofensivo pues afecta o puede llegar a afectar varios bienes jurídicos protegidos por el ordenamiento penal. Segundo, obedece a organizaciones delincuenciales sofisticadas. Tercero, el terrorista demuestra con su actitud una insensibilidad frente a los valores superiores de la Constitución Política, que son un mínimo ético, al atentar indiscriminadamente contra la vida y dignidad de las personas.

Estas connotaciones del terrorismo si bien hacen necesarias las acciones dirigidas a combatirlo no implican per se que se puedan violar normas relativas a los derechos humanos o al derecho internacional humanitario (en adelante DIH), como en efecto ha sucedido en Colombia.

A pesar de masivas violaciones a derechos humanos, en general la Corte Constitucional considera que todas las medidas para la represión y sanción de los atentados terroristas están en armonía "con la protección de los derechos fundamentales $\mathrm{y}$, en general, con el cumplimiento de los fines constitucionales del Estado". Se entiende entonces que todas ellas involucran o son aplicables a los integrantes de las Farc-EP, bajo la premisa de grupo terrorista y que, algunas de sus acciones son terroristas.

Junto a estas consideraciones se encuentran las tesis que propugnan por considerar la inexistencia de un conflicto armado interno y otras que argumentan que las FarcEP son terroristas.

¿Desde la perspectiva del conflicto armado interno, y de acuerdo con la jurisprudencia de la Corte Constitucional colombiana se puede establecer que las Farc son terroristas?

\section{METODOLOGÍA}

El presente estudio ha sido analítico, cualitativo y descriptivo de la doctrina nacional e internacional y de la jurisprudencia de la Corte Constitucional colombiana sobre el terrorismo de las Farc-EP. En todo el trabajo se tuvieron como referente los convenios y tratados internacionales suscritos y ratificados por Colombia. Al efecto se utilizó el método analítico de investigación, el cual permitió dividir el problema objeto de investigación en sus partes; del mismo modo se acudió al método no experimental descriptivo, que proporcionó todo un extenso material que analizado a la luz de la investigación socio jurídica se acerca a conclusiones científicas.

\section{INTRODUCCIÓN}

Sea lo primero aclarar que aquí no se habla del terrorismo que proviene de agentes del Estado, funcionarios o de particulares que actúan con su aquiescencia y que provocan actos de terror o de terrorismo, que son mayormente generadores de crímenes que tienen la particularidad de no ser visibles para la sociedad. Valga 
explicar que este estudio no tiene en cuenta el terrorismo paramilitar ni el del Ejército de liberación Nacional (ELN). Tampoco caben aquí, por ejemplo, la comisión de crímenes contra personas protegidas de forma organizada y sistemática, delitos en los que la mayoría de medios masivos de comunicación se han encargado de tergiversar la realidad, de tal modo que la sociedad no perciba el crimen y mucho menos sepa o cuestione a sus autores. Este es pues, el llamado terrorismo de Estado.

Colombia ha vivido por cinco décadas enfrentamientos entre las Farc-EP, el ELN y la fuerza pública colombiana (Ejército y Policía). En esos enfrentamientos los grupos de guerrillas han efectuado en determinados momentos acciones terroristas. A pesar de ese aspecto de terror o de terrorismo, por el cual se argumenta que estos grupos no son parte del conflicto, debido a que no cumplen los requisitos consagrados en el derecho internacional. Lo cierto es que para buena parte de la doctrina colombiana ha existido un conflicto armado de naturaleza no internacional; en ese sentido, en este trabajo se analiza la jurisprudencia constitucional colombiana respecto al conflicto armado interno y de allí se deduce si las Farc-EP son terroristas o no.

Para comprender el tema del terrorismo de las Farc-EP, en primer lugar, es importante entender que el terrorismo no solo proviene de grupos insurgentes o al margen de la ley, debe tenerse en cuenta que el terrorismo también proviene del Estado y de sus instituciones. Sin embargo, en el enfoque de este artículo solamente se tiene en cuenta el terrorismo clásico o convencional establecido en los artículos 144 y 343 del Código Penal colombiano. En segundo lugar, es pertinente analizar el terrorismo y si efectivamente las Farc-EP son o no un grupo terrorista; no obstante, es de esclarecer que en este escrito no se estudian las implicaciones que han tenido para el país el hecho de que no se declare o no se reconozca la existencia de un conflicto armado interno durante el siglo pasado y lo que va de este.

Aclarado esto, hay que señalar que las Farc-EP han sido objeto de concienzudos exámenes referidos a si efectivamente son terroristas; o si son parte en el conflicto armado colombiano, lo que trae como consecuencia que se denominen rebeldes, sediciosos o insurgentes, entre otros. En cualquier caso, lo estrictamente necesario es definir; en primer lugar, si en Colombia hubo un conflicto armado de naturaleza interna, y analizar de conformidad con la jurisprudencia constitucional si se dan los diferentes elementos necesarios para que se pueda decir que existe o existió conflicto armado. En segundo lugar, determinar si en medio del conflicto armado interno se pueda construir la base teórica necesaria para señalar sin mayores ambages que las Farc son terroristas.

Hoy (2015) es factible incluir dentro del conflicto armado, aspectos que durante décadas fue imposible reconocer; esto es que las acciones terroristas hacen parte de la dinámica de algunos conflictos armados internos en los que hay guerra asimétrica. Igualmente, el análisis que aquí se aborda indaga el porqué de manera implícita en este año 2015 por la vía del diálogo negociado entre gobierno y las Farc-EP se reconoció el conflicto armado interno y el estatus de beligerancia. Ante esa voluntad de paz, 
los acuerdos y la posterior firma de estos surge un modelo de justicia transicional necesario para solventar los problemas derivados del conflicto.

En ese modelo de justicia transicional las Farc-EP y el Gobierno nacional necesariamente salen beneficiadas; el grupo guerrillero en la medida en que se reconoce como parte del conflicto y a sus integrantes como beligerantes; el Gobierno en cuanto obtiene un reconocimiento universal por lograr la paz y por supuesto las víctimas del conflicto armado interno con ocasión de su reconocimiento masivo por vía administrativa, lo cual ha permitido que existan hoy más de 6,8 millones de víctimas debido al conflicto armado interno, según Paula Gaviria, directora de la Unidad de Víctimas; a estas víctimas se les está reparando y se les irá a reparar los daños causados con ocasión del conflicto armado interno (Periódico el Colombiano, 30/01/2015).

\section{LOS REQUISITOS PARA DETERMINAR LA EXISTENCIA DEL CONFLICTO ARMADO}

En aras a comprobar la existencia o no del conflicto armado en Colombia, es menester analizar lo contemplado en las decisiones más importantes de la Corte Constitucional colombiana. La investigación se remonta a la década final del siglo anterior, donde no se reconocía la existencia de un conflicto armado interno (ya existiendo la Corte como tal). Desde la Sentencia C-574 de 1992, por medio de la cual se realiza el control de constitucionalidad de los Convenios Internacionales de Ginebra y los dos protocolos adicionales, se establece el carácter normativo de dichos acuerdos y la aplicación que tiene cada uno respecto al conflicto armado que esté en desarrollo; con el fin de proporcionar unas garantías mínimas a las personas inmersas en el conflicto, por consiguiente establece la aplicación de los Convenios antes descritos, los cuales no obedecen al estatus jurídico de las partes en conflicto, si no que estas siguen a las actuaciones desplegadas por las partes; desmitificando la idea, de que al declararse el conflicto armado el carácter jurídico de las partes contendientes adquiere una valoración diferente.

La aplicación de los Convenios y del presente Protocolo, así como la celebración de los acuerdos previstos en estos instrumentos, no afectarán al estatuto jurídico de las Partes en conflicto. La ocupación de un territorio y la aplicación de los Convenios y del presente Protocolo no afectarán al estatuto jurídico del mismo (Corte Constitucional, Sentencia C-574-92, M.P. Ciro Angarita Barón).

Solamente es a partir de la Sentencia C- 205 de 1995 en la que se evalúa el acogimiento del protocolo adicional II a la legislación interna, en el que se comienza a analizar el conflicto armado interno y de igual forma se establece el estatus de norma Ius cogens entendida como una norma de carácter imperativo, perteneciente al derecho público internacional, la cual nace de un proceso consuetudinario, de carácter irreductible, no transigible, que obedece al desarrollo de las sociedades civilizadas y cuyo propósito es dar soporte al $\mathrm{DIH}$, con el fin último de velar por 
la protección de los derechos humanos con relación o en desarrollo del conflicto armado interno (Corte Constitucional, Sentencia C-225-95. M.P. Alejandro Martínez Caballero). De ahí que el profesor Aponte argumente que la Corte Constitucional en esta decisión enfatizó:

que la perspectiva de la humanización de la guerra no significa que el Protocolo II esté legitimando la existencia de los conflictos armados internos o el recurso a los instrumentos bélicos por grupos armados irregulares. Lo anterior, toda vez que la paz no debe ser entendida tan sólo como ausencia de conflictos, sino como la posibilidad de tramitarlos pacíficamente" (2010, p. 72).

En esta misma decisión, la Corte incorpora el denominado Bloque de Constitucionalidad, con el fin de asegurar la permanencia y obligatoriedad del contenido material del mismo, con ese término se conoce a aquellas normas y principios que, sin aparecer formalmente en el articulado del texto constitucional, son utilizados como parámetros del control de constitucionalidad de las leyes, por cuanto han sido normativamente integrados a la Constitución, por diversas vías y por mandato de la propia Constitución.

Esta obligación surge de la imperatividad de las normas humanitarias y su integración en el Bloque de Constitucionalidad, como bien señala Arango (2004, p. 93) esta "se deriva que el Estado colombiano deba adaptar las normas de inferior jerarquía del orden jurídico interno a los contenidos del Derecho Internacional Humanitario con el fin de potenciar la realización material de dichos valores".

En la misma providencia en comento (C-225 de 1995) se establecen los parámetros para determinar la existencia de un conflicto armado de carácter no internacional, haciendo la distinción entre "guerra civil y conflicto armado interno". Se afirma, en primer lugar, que no se necesita un nivel de intensidad, duración, control territorial y generalización tal como sí ocurre en una guerra civil para que sean aplicadas las normas humanitarias del Protocolo II. En segundo lugar, alude al reconocimiento del estatuto de beligerancia, el cual es otorgado por terceros Estados o por la comunidad internacional, con base en las circunstancias específicas que rodean a uno y otro tipo de conflicto, mas no por la adopción y aplicación de las disposiciones de este instrumento, infiriendo que para adquirir el estatus de conflicto armado interno, no obedece meramente a los aspectos establecidos en el protocolo adicional II, por el contrario, dicho estatus obedece a un análisis objetivo sobre la situación que se presenta en contexto; haciendo más clara las situaciones en las cuales debe intervenir el Derecho Internacional Humanitario (Corte Constitucional, Sentencia. C-225-95. M.P. Alejandro Martínez Caballero).

Los requisitos para la existencia de un conflicto armado interno se encuentran taxativamente descritos en el artículo $1^{\circ}$ del Protocolo II de 1977 que indica que:

El presente Protocolo, que desarrolla y completa el artículo 3 común a los convenios de Ginebra del 12 de agosto de 1949, sin modificar sus actuales condiciones 
de aplicación, se aplicará a todos los conflictos armados que no estén cubiertos por el artículo $1^{\circ}$ del protocolo adicional a los convenios de Ginebra del 12 de agosto de 1949 relativo a la protección de las víctimas de los conflictos armados internacionales (Protocolo I) y que se desarrollen en el territorio de una alta parte contratante entre sus fuerzas armadas y fuerzas armadas disidentes o grupos armados organizados que, bajo la dirección de un mando responsable, ejerzan sobre una parte de dicho territorio un control tal que les permita realizar operaciones militares sostenidas y concertadas y aplicar el presente protocolo.

Estos requisitos, en opinión de Valcárcel trayendo a colación a Michael Fruhling, se dan; es decir, en Colombia hay conflicto armado interno y en él se interrelacionan diversos factores que tienden a nutrir su reproducción: las ideologías justificatorias de la violencia, las exclusiones políticas, económicas y sociales, la producción y el tráfico de drogas, el comercio ilícito y la proliferación de armas, el peso de otros intereses económicos y el empleo de la guerra como modus vivendi"(Valcárcel, 2007, p. 112).

Para otros autores, en Colombia no existe un conflicto armado interno, Botero señala que "los grupos violentos terroristas que nos agreden como 'partes' de un conflicto interno armado; sobre todo, no ejercen dominio territorial, que es condición explícita y determinante. Por ende, todas las derivaciones de esa definición no tienen piso legal" (Botero, 2012).

Esta última apreciación contradice la opinión de la Corte que por medio de la Sentencia C-360-06 determinó la incidencia de las masacres en el desarrollo de conflicto; en consecuencia, la Corte señala la existencia del conflicto armado y hace alusión a las masacres perpetradas por grupos irregulares en zonas donde la presencia del Estado es precaria y el poder absoluto recae en diversos grupos que se encuentran al margen de la ley; de forma específica, dicha providencia evalúa la masacre llevada a cabo en el municipio de Mapiripán, departamento del Meta; la cual tuvo ocurrencia bajo el contexto del conflicto armado interno colombiano, allí quedó en entre dicho la eficacia del aparato judicial para la investigación y posterior juzgamiento de personas que desarrollan dichas acciones.

Ciertamente la masacre fue perpetrada en el contexto del conflicto armado que vive internamente Colombia; comprendió un gran número de víctimas -que fueron ejecutados o fueron desplazadas- y tuvo lugar en una región remota y de difícil acceso del país, entre otros factores. Sin embargo, en este caso la complejidad del asunto también está ligada a las dificultades provocadas en la investigación, que tuvieron su origen en las propias conductas activas y omisivas de autoridades administrativas y judiciales del Estado (Corte Constitucional, Sentencia C-370-06 M.P. Marco Gerardo Monroy Cabra).

Asimismo, en Sentencia C- 291-2007 se establece que la existencia de un conflicto armado, bien sea interno o internacional, no debe limitarse a lo establecido en los protocolos adicionales y los convenios de Ginebra, dado que en el desarrollo de los conflictos armados actuales se presenta un dinamismo y volubilidad, haciendo necesario una interpretación objetiva para determinar la existencia de un conflicto 
armado dentro de un Estado o entre este y otro Estado, con el propósito de regular las acciones militares desplegadas por los grupos contendientes, por parte del DIH. La Corte Constitucional en Sentencia C-291 del 2007 recuerda lo acogido en el Tribunal Internacional para la Antigua Yugoslavia:

al establecer la existencia de un conflicto armado de carácter interno la Sala debe apreciar dos criterios: (i) la intensidad del conflicto y (ii) la organización de las partes [ver sentencia del caso Tadic, pár. 562]. Estos criterios se utilizan 'solamente para el propósito, como mínimo, de distinguir un conflicto armado de actos de delincuencia, insurrecciones desorganizadas y de corta duración, o actividades terroristas, que no están sujetas al Derecho Internacional Humanitario' [sentencia del caso Tadic, pár. 562]. (...). En consecuencia, un cierto grado de organización de las partes será suficiente para establecer la existencia de un conflicto armado (...). Esta posición es consistente con otros comentarios autorizados sobre el tema (Corte Constitucional, Sentencia C-291-2007. M.P. Sigifredo Espinosa).

En concreto, los dos criterios objetivos son, por un lado, la intensidad del conflicto y, por otro, la organización de las partes, lo cual es recurrir a factores eminentemente objetivos. Luego, entonces, clarifica todo el articulado definido en los artículos 135 al 164 del Código Penal, los cuales tienen como elemento normativo del tipo penal. La Sentencia C-291 de 2007 permitió que la Corte se pronunciara en cuanto a la tipificación penal en el ordenamiento interno de distintas violaciones del DIH. Para la Corte Constitucional el concepto de conflicto armado toma una connotación diferente cuando se trata de víctimas de violación al DIH y crímenes de guerra, con el fin de reconocer e identificar a las víctimas de tales violaciones, luego, entonces, la Corte Constitucional apeló a la jurisprudencia internacional, la cual ha establecido que conflicto armado es definido como:

el recurso a la fuerza armada entre Estados, o la violencia armada prolongada entre las autoridades gubernamentales y grupos armados organizados, o entre tales grupos, dentro de un Estado". Se concluye en la sentencia que la "existencia de un conflicto armado se determina jurídicamente con base en factores objetivos, independientemente de la denominación o calificación que le den los Estados, Gobiernos o grupos armados en él implicados (Corte Constitucional, Sentencia C-291-2007. M.P. Sigifredo Espinosa).

De acuerdo con esa consideración, los hechos de violencia ocurridos en el interior de un Estado deben ser examinados con la mayor objetividad posible, analizando las particularidades de cada caso, ya que por más violentos, pueden no tener la intensidad que el intérprete estima, se requieren para cumplir dicho criterio, es decir, no se pueden clasificar como que dan cabal cumplimiento al requisito exigido por el derecho internacional para la existencia de un conflicto armado. El segundo requisito si ha sido cumplido por las guerrillas colombianas, pues estos grupos sí han tenido un alto grado permanente de organización. 


\section{CONFLICTO ARMADO, TERRORISMO Y VÍCTIMAS}

Un primer aspecto importante al definir si hay conflicto armado interno, tiene que ver con el reconocimiento a las víctimas, por lo tanto hay que analizar si al ser víctimas del terrorismo no podrían ser tenidas en cuenta como víctimas del conflicto armado. Así pues, es claro que las víctimas que hoy existen (6 millones de desplazados forzados y un millón de personas afectadas por otros hechos victimizantes), según un informe de la ONU, lo convierte en el segundo país del mundo con más víctimas de desplazamiento, después de Siria que tiene 6,5 millones, esta cifra y tal reconocimiento de calidad de víctima son posibles gracias a reconocer que hay conflicto armado interno.

Esto se puede colegir debido a que el reconocimiento de la existencia de conflicto armado interno en Colombia, implica a la luz del DIH que las víctimas del conflicto armado interno sean reconocidas de manera masiva. Igualmente permite que sus derechos a la verdad, justicia, reparación y garantía de no repetición se pueda intentar lograr. Además, se puede solicitar el respeto absoluto al DIH que de conformidad con los Convenios de Ginebra y sus protocolos adicionales, se aplica durante y después del conflicto internacional o de un conflicto armado interno.

Un segundo elemento, el cual está íntimamente ligado a la existencia del conflicto armado y a la posibilidad de lograr justicia por parte de las víctimas, es el que tiene que ver con el desplazamiento forzado como unos de los principales delitos cometidos con ocasión del conflicto; por lo tanto, la Corte analiza este concepto, describiendo como elementos esenciales desarrollados a nivel normativo y jurisprudencial los siguientes:

El traslado o migración dentro del territorio nacional; la dejación del lugar que habitualmente sirve de residencia o donde se desarrollan actividades económicas; el carácter forzado y no voluntario de esa decisión; la amenaza directa contra la vida, la integridad física y/o la seguridad o libertad personales como razones de esta decisión; v) el conflicto armado interno como fuente o causa generadora de los hechos que originan la amenaza. En el caso de la norma acusada, este último elemento resulta de la remisión que ella hace en su parte final a las 'violaciones a las que se refiere el artículo $3^{\circ}$ de la presente ley', norma que a su turno emplea el concepto de conflicto armado interno como referente y común denominador de los hechos que originan la calidad de víctimas (Corte Constitucional, Sentencia C-250 de 2012 M.P. Humberto Antonio Sierra Porto).

De lo cual, se puede inferir que si bien es cierto que no necesariamente el desplazamiento forzado se presenta con ocasión y en desarrollo del conflicto armado; este se presenta en gran mayoría en dicho contexto, por ende, se relaciona de forma directa con la existencia del conflicto.

En esta línea argumentativa, por medio de la Sentencia C- 250 del 2012, que analiza el artículo tercero de la Ley 1448 del 2011, respecto del cual se establecen las medidas de reparación integral para las víctimas del conflicto armado interno; asimismo dicha normativa establece que serán víctimas del conflicto armado: 
aquellas personas que individual o colectivamente hayan sufrido un daño por hechos ocurridos a partir del $1^{\circ}$ de enero de 1985 , como consecuencia de infracciones al Derecho Internacional Humanitario o de violaciones graves y manifiestas a las normas internacionales de Derechos Humanos, ocurridas con ocasión del conflicto armado interno (Corte Constitucional, Sentencia C-250 del 2012. M.P. Humberto Antonio Sierra Porto).

En conclusión, dicha providencia permite comprender la configuración legislativa que se le ha dado al conflicto armado.

Más recientemente, con la Sentencia C-781 del 2012 se realiza una demanda de inconstitucionalidad contra el artículo $3^{\circ}$ (parcial) de la Ley 1448 de 2011, la Corte mencionó varios aspectos importantes del conflicto armado ya que se discutía principalmente la expresión "con ocasión del conflicto armado". Hace una alusión del conflicto armado no internacional, en el ámbito del DIH, haciendo mención a los Convenios de Ginebra (1949) y el protocolo II adicional en su artículo primero del año 1977 , los cuales dan un punto de referencia para establecer el conflicto armado. Dentro de dichos aspectos se destaca que "la situación de violencia que tenga ocurrencia en el territorio de una alta parte contratante; que se trate de organizaciones con un grado de organización, y que les permita realizar acciones sostenidas". Lo cual en efecto, y tal como se decía más arriba lo cumple según en opinión de buena parte de la doctrina nacional, con mayor o menor rigurosidad las Farc-EP (Huertas, 2014).

Para la Corte, la expresión "con ocasión del conflicto armado" inserta en la definición operativa de "víctima" establecida en el artículo $3^{\circ}$ de la Ley 1448 de $2011, \ldots$. La expresión "con ocasión del conflicto armado" tiene un sentido amplio que cobija situaciones ocurridas en el contexto del conflicto armado. A esta conclusión se arriba principalmente siguiendo la ratio decidendi de la Sentencia C-253A de 2012, en el sentido de declarar que la expresión "con ocasión de" alude a "una relación cercana y suficiente con el desarrollo del conflicto armado".

Así mismo la Corte constitucional ha entendido el conflicto armado desde una noción amplia, es decir, no se refiere al conflicto armado aquel que se derive únicamente a: "las confrontaciones estrictamente militares, o a un grupo específico de actores armados con exclusión de otros, ha sido interpretada en un sentido amplio que incluye toda la complejidad y evolución fáctica e histórica del conflicto armado interno colombiano" (Corte Constitucional, Sentencia C-781/12 M.P. María Victoria Calle Correa).

Por otro lado, la Corte ha establecido a través de esta misma (C-781-12) los siguientes puntos de referencia para analizar la conexidad de elementos que tienen relación con el desarrollo y la existencia del conflicto armado.

Los desplazamientos intraurbanos, el confinamiento de la población; la violencia sexual contra las mujeres; la violencia generalizada; las amenazas provenientes de actores armados desmovilizados; las acciones legítimas del Estado; las actuaciones atípicas del Estado; los hechos atribuibles a bandas criminales; los hechos atribuibles 
a grupos armados no identificados, y por grupos de seguridad privados, entre otros ejemplos. Si bien algunos de estos hechos también pueden ocurrir sin relación alguna con el conflicto armado, para determinar quiénes son víctimas por hechos ocurridos en el contexto del conflicto armado interno, la jurisprudencia ha señalado que es necesario examinar en cada caso concreto si existe una relación cercana y suficiente con el conflicto armado interno (Corte Constitucional, Sentencia C-781-12 M.P. María Victoria Calle Correa).

\section{APLICACIÓN DEL DIH}

Según el DIH sí hay conflicto armado interno en Colombia, puesto que se presentan todos los elementos constitutivos de un conflicto armado no internacional.

Este conflicto armado obedece a unos aspectos fácticos-históricos, que no obstante la existencia de violencia generalizada, incluso, sistemática, dirigida contra la población civil y con conocimiento de dicho ataque proveniente del Estado, de un grupo u organización, nunca se reconoció la existencia del conflicto y tampoco se establecieron las partes del mismo con claridad; todo lo cual conlleva que hayan existido limitaciones relacionadas con la real aplicación y castigo por violaciones al DIH.

La aplicación del DIH es independiente del reconocimiento del estatus de beligerancia, empero, este es un tema bastante espinoso, debido a que para ningún Estado es fácil aceptar u otorgar ese estatus, pues llevaría implícita la aceptación jurídica de que existe una guerra, entre dos o más grupos que se disputan el control del mismo Estado. Respecto a la beligerancia se requieren consonantes requisitos "en primer lugar tiene que ser un ejército jerarquizado, en segundo lugar en este ejército debe haber un control territorial y en tercer lugar, ese ejército está obligado a dar cumplimiento al DIH (Torres, 2013, p. 272). Sin embargo, es claro que los Estados en los que hay conflictos armados se niegan a reconocer la beligerancia de sus contendientes armados que ejecuten actos violentos. Esto tiene una razón bien importante para el caso de Colombia, no se reconoció el conflicto o la situación de beligerancia, puesto que el Estado colombiano ha adquirido diversas obligaciones contractuales a nivel internacional, así por ejemplo, está obligado a actuar bajo los parámetros establecidos en los Convenios de Ginebra y sus Protocolos adicionales. Lo mismo sucede con el Estatuto de la Corte Penal Internacional de 1998. El desconocimiento del Convenio o tratado o de alguno de sus apartes, implica sanciones tanto políticas como económicas, que en ocasiones generan intervenciones militares.

Ahora bien, unido al reconocimiento de la beligerancia se encuentra la posibilidad del grupo insurgente de recibir apoyo, de tipo político y especialmente económico tanto de carácter nacional como internacional, del mismo modo, esa legitimidad de las actuaciones desarrolladas por grupos insurgentes permite un apoyo militar internacional a dichas organizaciones. 


\section{HISTORIA NORMATIVA DEL TERRORISMO EN COLOMBIA}

En la década que inicio en 1980 las organizaciones terroristas colombianas se aumentaron y fueron mucho más letales, lo que incluía acciones terroristas. Este álgido momento se debió a que eran totalmente dependientes del mayor incentivo en esos momentos del narcotráfico; su motivación estaba asociada a disminuir la capacidad de acción estatal en su persecución y, finalmente, lograr acuerdos de tipo político que les permitiera efectuar un tráfico de drogas de manera legal. Ese terrorismo también lo produjeron los movimientos guerrilleros apoyados o financiados por carteles de la droga de Medellín y Cali; entre estos grupos las Farc-EP se sirvieron de esos recursos para aumentar sus frentes y su expansión fue mayor. Torres recuerda que "En Colombia la violencia terrorista llega a ser el principal instrumento del cártel de Medellín para mantener o, al menos, intentar conservar sus privilegios", más adelante agrega que:

No obstante, para ganar el «pulso» al Estado y debido a las fisuras de una organización criminal que producía constantemente terror y miedo, en muchas ocasiones innecesario, se requería la violencia extrema del terrorismo. Casos como el de las cien bombas que estallaron contra supermercados, entidades bancarias, colegios e instalaciones eléctricas y telefónicas en septiembre a diciembre de 1989; junto a los ataques terroristas contra el avión de Avianca en pleno vuelo y el atentado al Departamento Administrativo de Seguridad (DAS), atentados en los que se sindicaba a los extraditables, indican hasta dónde tenían el poder de cometer atentados terroristas en todo el país y de convertirse en una afrenta permanente para los distintos gobiernos (2013, pp. 109-130).

Junto a este clásico terrorismo sucedían acciones de terror o terrorismo de manera frecuente en los ya tradicionales grupos como las Farc-EP o el ELN quienes efectuaban terrorismo con otra motivación, el cual era "adornado" con el todavía subsistente discurso del altruismo de toma del poder por medio de la lucha armada.

En ese contexto, los medios masivos de comunicación fueron fundamentales para los grupos terroristas respecto a expresar sus demandas. El terrorismo de Pablo Escobar Gaviria contó con el apoyo "gratuito" de los mass media, esa actitud favoreció su accionar y le permitió obtener los réditos que quiso. En ese aspecto, inclusive, la sociedad en general se vino a complacer debido a que conocía de primera mano la cara del terror. La actividad publicitaria de los medios también se vio fortalecida; el terrorismo y el miedo que representaba ocasionaron que todos estuvieran pendientes de los medios y de sus informaciones, lo cual beneficiaba a las empresas pautadoras. Por consiguiente Torres (2013, p. 121) señala que el manejo mediático del terrorismo doméstico convencional, hace un uso del lenguaje y de la información, la cual no solo aliena al grupo poblacional mayoritario, sino que criminaliza a los que no están alienados. 
Esta situación se ha dado en las últimas décadas, de tal manera que en la medida en que las acciones terroristas aumentaban, la cobertura informativa hacia lo propio. Los terroristas incrementaban el número de acciones y su letalidad, de ahí lograron no solo la desestabilización del país, sino que el público terminó aceptando el vivir con el terror y en general se desensibilizó, en consecuencia un acto terrorista tras otro, era algo normal en la vida cotidiana del país.

En definitiva, los medios masivos de comunicación hicieron eco del terrorismo, y este recrudeció sus acciones con el principal objetivo de lograr concentrar una mayor audiencia durante más tiempo. Al contrario de mejorar la seguridad ciudadana, con el accionar de medios y terroristas, se aumentó la criminalidad en general; todo producto del caos.

Arango, haciendo una reseña sobre lo que es el terrorismo declaro que:

En Latinoamérica, el terrorismo se originó debido a conflictos políticos localizados. La gran innovación, fue la creación de las guerrillas urbanas, las cuales, basadas en la ideología de izquierda desplazaron las actividades terroristas del campo a la ciudad. Uno de los principales ejemplos es el grupo maoísta peruano Sendero Luminoso, el cual, debido a sus brutales tácticas para desestabilizar al estado, pasó a la historia como uno de los más sanguinarios (2005, p. 15).

Dicho lo anterior, es obligado indicar que en un análisis del terrorismo en Colombia es necesario ubicar el momento en que este surgiera en la ley colombiana como delito. Ciertamente este crimen surge taxativamente desde 1978, por medio del Decreto 1923 denominado "Estatuto de Seguridad" durante el gobierno de Julio Cesar Turbay Ayala. En el caso colombiano durante la vigencia -al menos- del "Estatuto de Seguridad" del gobierno de Julio César Turbay permitió la penalización de las protestas urbanas, el "castigo social". "De tal modo que con base en esas normas ambiguas se podía criminalizar de manera indiscriminada y colectiva" (Aponte, 2006, p. 487).

En aquel momento fue usado el tipo penal de terrorismo como medio para combatir, por un lado a las guerrillas, especialmente las acciones violentas del Movimiento 19 de Abril - M.19; y por otro lado para perseguir el inconformismo popular, llevado a cabo por obreros y campesinos. Este estatuto también llamado antiterrorista en su exposición de motivos decía:

periódicamente se han venido reiterando y agudizando las causas de perturbación del orden público, que crean un estado de inseguridad general y degeneran en homicidios, secuestros, sedición, motín o asonada, o en prácticas terroristas dirigidas a producir efectos políticos encaminados a desvirtuar el régimen republicano vigente o en la apología del delito... 
En general esta disposición les daba garantías a los militares para investigar juzgar y condenar civiles, además de la posibilidad de retener personas sin orden judicial, el practicar arrestos, allanamientos y registros, junto a otras medidas como la intercepción de teléfonos.

Esta ley fue "mejorada" durante el gobierno de Virgilio Barco Vargas (19861990), llamándose el Estatuto para la Defensa de la Democracia y el cual también iba dirigido a combatir por la vía laxa del tipo penal terrorismo, a las personas disidentes con el gobierno. Aunque el discurso gubernamental era dirigido a que la dureza del Estatuto se debía a la necesidad de luchar contra los actos terroristas del narcotraficante Pablo Escobar y de sus enemigos el Cartel de Cali, y de otras organizaciones criminales como eran los insipientes grupos paramilitares que de la mano de la familia Castaño y del apoyo del Gobierno serían en la siguiente década el peor mal del país.

Igualmente, como aspecto vital para tener en cuenta es que la Corte Constitucional considera que en 1985 el Estado colombiano asume la existencia del conflicto armado, puesto que a nivel jurídico se establecen los primeros decretos sobre el tema:

El Estado colombiano asumió la existencia de una confrontación armada y fue expedida la primera Ley de Orden Público que conoce el país, que convirtió en permanentes varios de los 60 decretos que el Gobierno había adoptado en uso de las facultades de conmoción interior. Esta ley, marca el inicio de una lucha frontal contra los grupos armados al margen de la ley y, por ende, de un escalamiento de la confrontación bélica interna en el país (Corte Constitucional, Sentencia C-250 de 2012, M.P. Humberto Sierra Humberto).

El 27 de noviembre de 2001 en Colombia se dio inicio a la estrategia integral contra el terrorismo, denominada: "El Camino hacia la Paz y la Estrategia contra el Terrorismo". Fue adoptado durante el gobierno de Andrés Pastrana Arango en el 2000, y promovía, entre otros, la creación de "frentes locales de seguridad" y la adopción de medidas para estrechar la cooperación entre los civiles y las autoridades en la lucha contra el terrorismo. En el marco de esta política, sería promulgada la Ley de Seguridad Nacional. Esta ley fue presentada como "principio de un conjunto de normas orientadas a acabar la guerra". Socavaba principios básicos del Estado de derecho, ordenando la subordinación de las autoridades civiles a las Fuerzas Armadas, dando amplios poderes a estas, en materia de Policía Judicial y control de movimiento y residencia de la población civil, y estableciendo un estado de excepción de facto y permanente (CIJ, 2005).

Ya en la Ley 599-2000 (actual Código Penal) señala en los artículos 343 y 144 el terrorismo; siendo el del artículo 343 el más laxo, este tipo penal ha permitido acabar con los clásicos delitos políticos (rebelión, sedición, conspiración), convirtiendo a buena parte de los individuos que cometen conductas de esa índole, como terroristas. Por los ataques terroristas sucedidos en EE. UU., unidos a brotes de 
actos de terror de las Farc-EP y el ELN, es en este contexto social cuando comienza a ser preocupante el delito de terrorismo. Dado que es masivamente utilizado en el gobierno del "derechista" Álvaro Uribe Vélez, como medio disuasorio de acciones pacíficas contra el gobierno, denominando a campesinos, obreros, maestros, entre otros como terroristas o auxiliadores del terrorismo. Este rótulo se aplicó a todos aquellos que disentían pública o privadamente de sus excesos y de sus crímenes de Estado.

En ese gobierno fue muy popular la denominada "Política de Defensa y Seguridad Democrática", entre 2002 y 2010, fueron una serie de acciones que se desarrollaron en coordinación con todas las entidades del Gobierno y las demás ramas del poder. El objetivo fundamental de dicha política fue la recuperación del control del Estado sobre la mayor parte del territorio nacional, particularmente aquel afectado por la actividad de grupos armados ilegales y narcotraficantes. Al término de la primera administración de Uribe, los resultados fueron según los medios masivos de comunicación, contundentes. La percepción de seguridad en los colombianos había mejorado ostensiblemente y, con ella, la confianza inversionista y el progreso social (www.mindefensa.gov.co). Sin embargo, fue una política represiva muy violenta del presidente Uribe contra la disidencia política; las denuncias por violaciones masivas a los derechos humanos y al DIH son enormes. En su gobierno las detenciones ilegales sin límite y sin orden judicial, las redes de informantes que permitieron iniciar procesos sin base legal; además de los asesinatos de periodistas y sindicalistas, entre otros; ya fuera por agentes estatales o por civiles con su beneplácito fueron planeadas, organizadas y sistemáticas, todo lo cual sin mayor esfuerzo analítico son considerados delitos de lesa humanidad, es decir, son crímenes internacionales que inquietan la conciencia de la humanidad.

A pesar de tan cruento gobierno, aun cuenta con enorme acogida que lo llevó en 2014 a tener 19 senadores en el Congreso de la República incluido él; lo que demuestra la gran popularidad del partido político y la actualidad del populismo de su grupo político, especialmente del respaldo y legitimación de las falacias de sus políticas, teóricamente para mejorar la seguridad y preservar la democracia.

En concreto, en Colombia diversas leyes han tratado el tema del terrorismo desde el ámbito puramente penal, al menos en el presente siglo se tiene la instauración de la Ley 526 de 1999 que crea un departamento de información y análisis financiero con un enfoque en el lavado de dinero y financiamiento del terrorismo; luego surge la Ley 599-2000 (Código penal), la cual contiene en sus artículos 144 y 343 normas respecto al terrorismo, aunque con diferentes bienes jurídicos protegidos. Luego pasando por la Ley 733 de 2002 que contiene medidas contra el secuestro, terrorismo y extorsión y la Ley 1121 de 2006 que comprende numerosas medidas para la prevención, detección, investigación y sanción de la financiación del terrorismo; hasta la Ley 1142 de 2007, la cual surgió con la intención de mejorar la seguridad ciudadana y de convivencia, lo cual llevó a reformar el Código Penal y de Procedimiento Penal. 


\section{LAS DECISIONES DE LA CORTE CONSTITUCIONAL RESPECTO AL TERRORISMO}

El fenómeno del terrorismo es imposible analizarlo desligado del impacto que genera una visión estereotipada por parte de los medios masivos de comunicación y diferenciarlo de lo político y por supuesto de su propia naturaleza criminal.

Es sabido que las Farc-EP han cometido cuando menos, esporádicas acciones de terror o de terrorismo con una marcada tendencia a radicalizar las diferencias reales entre izquierda y derecha, entre ricos y pobres o cualquiera otra disparidad social. Analizado en ese contexto el conflicto armado interno en Colombia no se distingue entre terroristas y entre delincuentes políticos, lo que conlleva que todas las acciones emprendidas por diferentes gobiernos colombianos recuerdan el régimen de Bismarck en el cual tanto Alemania, Austria al igual que Rusia utilizaron todos los aparatos de seguridad que se dirigían a atacar a sectores de izquierda o sus simpatizantes con la utilización de medidas violatorias de los derechos humanos, además del empleo de normas de excepción que luego se practicaban cotidianamente; todas ellas con una tendencia a mantener los teóricos peligros que provienen de sectores inconformes con el gobierno. Otra forma de mantener vivo el problema era la internacionalización de este. Los asesinatos selectivos e inclusive masivos, provocaron huidas de estos países de individuos que tenían dotes de liderazgo estimulando el desánimo de los grupos inconformes y una crisis en la dirigencia de grupos con opciones políticas, impidiendo la creación de nuevos grupos y la limitación o anulación de la expansión de los mismos. Estos elementos y ese nefasto panorama fueron ciertamente aplicados en Colombia.

Se puede argumentar que ningún grupo terrorista de manera real provocaría un peligro serio para la estabilidad de cualquier gobierno. De hecho, esas acciones contra el terrorismo se fundamentan en su totalidad en el miedo y especialmente en su principal característica: lo etéreo que es este. En ese aspecto se encuentra que el miedo es supremamente contagioso; bien dirigido, como siempre sucede con los Estados que efectúan terrorismo y en aquellos déspotas, tiránicos o autoritarios que esporádicamente efectúan acciones de terror o de terrorismo desde el Estado, el miedo llega a ser el principal instrumento estatal para imponer su voluntad.

En el caso específico colombiano, podría pensarse que el sistema penal nacional, ante una situación de crisis institucional producto de acciones terroristas, en medio del conocido y antiguo conflicto armado; tiene la solución sin tener que recurrir a la ley penal excepcional. Como esto acontece, en distintas oportunidades, el Estado recurre a los estados de excepción en el que normas penales con carácter extraordinario permiten la persecución a criminales terroristas. Lo que sucede a menudo es que se continúa con esa clase de normas penales, ya en situaciones de total normalidad. Planteada la cuestión de esta manera, parece que la dificultad estriba en que las normas penales aplicadas en situaciones de anormalidad son muy severas, 
ya que restringen, modifican, suprimen, o eliminan derechos importantes para el ser humano, como son los derechos fundamentales o derechos humanos, que no deberían sufrir esa suerte. Para el Colectivo de Abogados José Alvear Restrepo en Colombia existe una política criminal que tiene dos aristas, de un lado, una política criminal estatal-formal, que es pública y, por otro lado, la paraestatal-real, que es oculta, por lo tanto esta es una "política criminal orientada a reprimir y criminalizar, sin reparos, la protesta popular y por esta vía a consolidar la pobreza, bien sea "apaciguando" a los que se levantan, o eliminándolos o encarcelándolos" (www.derechos.org/nizkor). De acuerdo con esas calificaciones se podría hablar de terrorismo estatal al menos durante el gobierno Uribe.

Continuando con la argumentación constitucional respecto al conflicto armado interno, la Corte Constitucional se pronunció mediante la Sentencia C-769/02, en cuanto a eliminar el acceso a amnistías e indultos por parte de responsables del delito de terrorismo, de acuerdo al artículo 150-17 de la Constitución.

Esa corporación recuerda el consenso internacional respecto a la gravedad de los actos constitutivos de terrorismo, los que legitiman la adopción en Colombia, "de convenios dirigidos a garantizar la prevención, represión y sanción de esa conducta, fundados en instrumentos amplios de cooperación internacional, en todo caso respetuosos tanto de la soberanía estatal, como de los derechos constitucionales de sus habitantes" (Corte Constitucional, Sentencia C-073/10. M.P. Humberto Antonio Sierra Porto). Por estas razones, la Corte reconoció a través del fallo C-1055/03 que el Convenio Internacional para la Represión de la Financiación del Terrorismo y otras normas similares son vehículos idóneos para el cumplimiento de "algunas importantes finalidades del ordenamiento constitucional colombiano, entre ellas la de poner en funcionamiento mecanismos para prevenir la comisión de este tipo de conductas, el logro de la paz y la vigencia de un orden social justo, todo en aras de cumplir el mandato impuesto por el artículo $2^{\circ}$ de la Carta que prescribe que las autoridades de la República están instituidas para proteger a todas las personas residentes en Colombia, en su vida y bienes.

En el mismo sentido la Corte manifiesta que:

Las conductas constitutivas de actos de terrorismo configuran un delito atroz, que afecta gravemente bienes constitucionales que conforman los pilares del modelo de Estado adoptado por la Carta Política, en especial la vida, la integridad personal, la dignidad humana y la búsqueda de la paz y un orden justo. Del mismo modo, tales conductas contradicen varias disposiciones del derecho internacional de los derechos humanos y del DIH, entre ellas aquellas que conforman el cuerpo normativo de carácter imperativo agrupado bajo el ius cogens. En consecuencia, las decisiones que adopte el legislador dirigidas a la implementar medidas para la prevención, represión y sanción del terrorismo son prima facie armónicas con el Estatuto Superior. 


\section{CONSECUENCIAS JURÍDICAS DE SER TERRORISTA}

El hecho de ser caracterizado como terrorista tiene serias implicaciones en aspectos no solo con el reproche social, sino en las penas, las que habitualmente son muy altas. Es tradicional que al terrorista y debido especialmente a la subjetividad, aumentada por los medios de comunicación, se le vea como un demonio al que se le nieguen derechos que rozan en violaciones a la dignidad humana. Múltiples tratados internacionales suscritos y ratificados por Colombia ${ }^{1}$ señalan que autores o partícipes de estos delitos no deben ser objeto de privilegios penales.

Una de las características de interpretación objetiva del terrorismo tiene que ver con que existe exclusión de la amnistía y el indulto para el delito de terrorismo, debido a que es un delito común, además por su extrema gravedad y al desconocimiento de valores superiores y menoscabo de derechos fundamentales (Sentencia C-695/02, M.P. Jaime Córdoba Triviño).

La amnistía extingue la acción penal y la pena mientras que el indulto extingue la pena. Es constitucional y conforme al derecho internacional no permitir las amnistías o los indultos a delitos de terrorismo, secuestro o extorsión, ya que no son delitos políticos, y ni siquiera conexos con estos. En una interpretación del $\mathrm{DIH}$, desde una perspectiva penal internacional, es de concluirse que a los autores o partícipes de delitos de terrorismo y delitos conexos como el secuestro, en cualquiera de sus modalidades, no son beneficiados con amnistías e indultos. En efecto, los tratados internacionales tipifican los delitos de terrorismo y secuestro como delitos atroces susceptibles de extradición o juzgamiento (Aut dedere, aut judicare), y en ningún caso se consideran delitos políticos aptos para ser beneficiarios de amnistías e indultos (Sentencia C-695/02, M. P. Jaime Córdoba Triviño).

1 En el sistema universal se encuentran los siguientes instrumentos relativos a la lucha antiterrorista: i) Convenio sobre las infracciones y ciertos otros actos cometidos a bordo de las aeronaves; ii) Convenio para la represión del apoderamiento ilícito de aeronaves; iii) Convenio para la represión de actos ilícitos contra la seguridad de la aviación civil internacional; iv) Protocolo para la represión de actos ilícitos de violencia en los aeropuertos que presten servicio a la aviación civil internacional; v) Convención sobre la prevención y el castigo de delitos contra personas internacionalmente protegidas, inclusive los agentes diplomáticos; vi) Convención internacional contra la toma de rehenes; vii) Convenio sobre la protección física de los materiales nucleares; viii) Convenio para la represión de actos ilícitos contra la seguridad de la navegación marítima; ix) Protocolo para la represión de actos ilícitos contra la seguridad de las plataformas fijas emplazadas en la plataforma continental; x) Convenio sobre la marcación de explosivos plásticos para los fines de detección; xi) Convenio internacional para la represión de los atentados terroristas cometidos con bombas; y xii) Convenio internacional para la represión de la financiación del terrorismo. En el sistema interamericano han sido adoptados los siguientes instrumentos: i) Tratado Interamericano de Asistencia Recíproca; ii) Convención para Prevenir y Sancionar Actos de Terrorismo Configurados en Delitos contra las Personas y la Extorsión Conexa cuando estos tengan Trascendencia Internacional; iii) Conferencia especializada interamericana sobre terrorismo. Plan de acción sobre cooperación hemisférica para prevenir, combatir y eliminar el terrorismo; iv) Segunda Conferencia Especializada Interamericana sobre Terrorismo. Compromiso de Mar del Plata; v) Carta Democrática Interamericana; vi) Fortalecimiento de la Cooperación Hemisférica para Prevenir, Combatir y Eliminar el Terrorismo; vii) Amenaza Terrorista en las Américas; y viii) Convención Interamericana contra el Terrorismo. 
El terrorismo es un delito común al que hay que aplicar el derecho penal común:

La razón de que los tratados internacionales tipifiquen el terrorismo y el secuestro como delitos comunes, se debe a que utilizan métodos para producir un clima de terror, dar publicidad a una causa e intimidar a un sector más amplio a fin de que se logren los objetivos que persiguen los terroristas. Así, la comunidad internacional ha determinado que el uso del terror indiscriminado contra objetivos civiles inocentes o el secuestro, no pueden ser considerados como delitos políticos ni conexos, porque ofenden la conciencia misma de la humanidad, la dignidad, la vida y los derechos fundamentales de las personas $\mathrm{y}$, por tanto, en ningún caso se puede estimar que tales conductas obedecen a móviles nobles o altruistas (Aclaración de voto de los magistrados Rodrigo Escobar Gil, Marco Gerardo Monroy Cabra y Álvaro Tafur Galvis, Sentencia C-695/02, M. P. Jaime Córdoba Triviño).

\section{CONCLUSIONES}

En Colombia el enfrentamiento armado ha existido y ha sido prolongado entre fuerzas armadas gubernamentales y las fuerzas de uno o más grupos armados. Los Convenios de Ginebra señalan la exigencia de que el enfrentamiento armado debe alcanzar un nivel mínimo de intensidad y las partes que participan en él deben poseer una organización mínima. Otros requisitos tiene que ver con la intensidad del conflicto y la estructura organizativa de las partes contendientes.

Estos requisitos, por supuesto las Farc-EP lo han cumplido. De lo cual se puede inferir, que en Colombia por razones políticas y económicas no se acepta la existencia del conflicto armado, a sabiendas de que la lucha armada ha permanecido por más de medio siglo a lo largo y ancho del territorio colombiano.

Al no reconocerse la existencia del conflicto, es evidente que en Colombia existen muchas contradicciones en cuanto la aplicación del DIH, por un lado no existe conflicto armado interno, pero a su vez hay un capítulo del Código Penal exclusivo para los delitos o conductas realizadas con ocasión y el desarrollo del conflicto. Esto ha permitido un alto grado de subjetividad al adecuar típicamente algunas conductas en esos tipos penales por lo tanto, a algunas personas se les aplica y a otros no.

Las sentencias de la Corte Constitucional determinan que en Colombia existe conflicto armado interno, aunque no señalan como requisito para reconocer el conflicto armado interno el hecho de admitir el estatus de beligerancia; este requisito obedece a la doctrina, aun así el conflicto armado interno fue y es una realidad ineludible.

Además constitucionalmente se ha determinado la necesidad de perseguir dentro de la legalidad a los terroristas. Para la Corte Constitucional las normas emanadas en diferentes gobiernos se ajustan al propósito del legislador de disuadir a todos aquellos que pretendan crear terror, alarma o zozobra. Igualmente, se ha definido de manera clara que el terrorismo no puede ser considerado como delito político. No obstante, que en esa consideración no quepa el terrorismo de Estado, el que ha 
gozado y hoy se aprovecha de la protección de amplios sectores de poder, los cuales lo crean, lo patrocinan o lo alientan y en esa medida es muy difícil pensar en que es, $o$ va a ser combatido de manera real y efectiva.

Un aspecto trascendental en este escrito es que después de muchos años, en el 2015 se logra constatar que la existencia del conflicto armado y sobre todo su no reconocimiento tuvo razones políticas y económicas. En cambio un análisis efectuado por parte de la gran mayoría de académicos de acuerdo con lo contemplado en los convenios de Ginebra y los protocolos adicionales, indica que las Farc-EP ha realizado operaciones militares concertadas, tienen muchos años de existencia, en ocasiones ha tenido un control territorial y cuenta con una estructura jerarquizada. Por lo tanto, desde la academia se ha precisado que se cumplen todos los requisitos para determinar que este grupo es parte en el conflicto armado interno y que en consecuencia hubo conflicto.

De otro lado, el terrorismo en Colombia se encuentra muy ligado al conflicto armado interno, debido a las posibilidades de utilizar acciones terroristas en un contexto de guerra asimétrica y porque el Estado hace uso del término en contra de no terroristas en lugar de enfrentar todos los problemas de tipo social. En ese orden de ideas el terrorismo ha sido parte del discurso político en varias décadas y en ese manejo mediático la casi totalidad de la sociedad colombiana ha venido asumiendo, por lo menos en algunas épocas, el terrorismo como el principal inconveniente de todo el pueblo colombiano, olvidando muchos otros problemas de tipo social quizás más importantes que el mismo terrorismo.

Por último, hay que destacar que el terrorismo puede ser sancionado ante instancias internacionales, ya sea a través de la Corte Penal Internacional siempre que se encuadre como un delito que cumpla las características de los delitos de lesa humanidad, también se puede investigar, juzgar y condenar a los miembros de grupos terroristas o a terroristas individuales siempre que cometan acciones de terror o de terrorismo y que sean una parte contrincante de un conflicto armado, ya sea interno o internacional por infracciones al DIH o por una violación sistemática y organizada los derechos humanos. En definitiva el terrorismo es objeto de persecución en tiempos de guerra o de paz en instancias nacionales o internacionales o en ocasiones de manera simultánea. Una actitud en contrario, implica que se desconozca la supremacía de las normas internacionales sobre las nacionales.

No obstante lo dicho, desde el Código Penal de 1936 existían tipos penales de rebelión que bien se podían asemejar al tipo penal actual de terrorismo.

\section{REFERENCIAS}

Albrecht, H.-J. (2006). Respuestas legislativas al 11 de septiembre. Un análisis comparado de la legislación antiterrorista. En Bueno, F. et al. (Dirs.). Derecho penal y criminología como fundamento de la politica criminal. Estudios en homenaje al profesor Alfonso Serrano Gómez. Madrid: Dikynson. 
Aponte, A. (2006). Guerra y derecho penal del enemigo. Bogotá: Ibáñez.

Arango, C. (s.f.). Terrorismo y seguro de terrorismo. Consideraciones de carácter jurídico, económico y social. Pontificia Universidad Javeriana.

Arango, M. (2004). El bloque de constitucionalidad en la jurisprudencia de la Corte Constitucional colombiana. Precedente Revista Jurídica. Icesi. Cali.

Botero, L. (2012). Marco jurídico para la paz: Inconstitucional e inconveniente. Medellín. Recuperado de http://www.pensamientocolombia.org/

Colectivo de Abogados José Alvear Restrepo.: Recuperado de http://www. colectivodeabogados.org/

Comisión Internacional de Juristas - CIJ. (2005). Colombia: Politicas del Gobierno socavan el Estado de derecho y consolidan la impunidad. 21 de septiembre.

Convenios de Ginebra 12 de agosto de 1949 Naciones Unidas.

Corte Constitucional, Sentencia C-574-92. M.P. Manuel José Cepeda Espinosa.

Corte Constitucional, Sentencia C-225-95. M.P. Alejandro Martínez Caballero.

Corte Constitucional, Sentencia C-578-2002. M.P. Manuel José Cepeda Espinosa.

Corte Constitucional, Sentencia C-370-06. M.P. Marco Gerardo Monroy Cabra.

Corte Constitucional, Sentencia C-291-2007. M.P. Manuel José Cepeda Espinosa.

Corte Constitucional, Sentencia C-250 del 2012. M.P. Humberto Sierra.

Corte Constitucional, Sentencia C-781-12. M.P. María Victoria Calle Correa.

Faivre, H. (31 de enero, 2006). Del Plan Colombia al Plan Patriota: Impacto del conflicto armado colombiano en el Ecuador, análisis de una estrategia de seguridad subregional. Revista Complutense de Historia de América. Recuperado el 22 de mayo de 2015 de http://revistas.ucm.es/index.

Huertas, O. (enero-diciembre, 2014). El principio de imprescriptibilidad de los delitos de lesa humanidad y su aplicación en el ordenamiento jurídico colombiano. Un estudio desde los derechos humanos y la interpretación jurídica. Revista Misión Jurídica, vol. 7.

Huertas, O., Torres, H. (2013). El concepto de terrorismo" de las Fuerzas Armadas Revolucionarias de Colombia Farc-EP: terroristas o subversivos. La instrumentalización del terrorismo. Bogotá, Colombia: Editorial Ibáñez.

Periódico El Colombiano, Unidad para la Atención a Víctimas quiere superar el asistencialismo, 30 enero de 2015.

Revista Semana, edición del 21 de octubre de 2014.

Torres, H. (enero-abril, 2013). Terrorismo y medio de comunicación. Pensamiento Jurídico, 36. Bogotá.

Torres, H. (2012). Derecho internacional humanitario y estatus de beligerancia. Revista Republicana, 12, enero-junio.

Torres, H. (2013). La delincuencia organizada transnacional en Colombia. Díkaion 22. 
Uprimny, R. (s.f.). ¿Existe o no conflicto armado en Colombia? Recuperado de http:// otramiradadelconflicto.wikispaces.com

Valcárcel, J. M. (2007). Concepto de conflicto armado interno y seguridad jurídica. Revista Prolegómenos- Derecho y Valores, vol. X. Bogotá, Colombia. 